\title{
The effect of temperature change on fluoride uptake from a mouthrinse by enamel specimens
}

Serdar Baglar ${ }^{1}$

Adil Nalcaci

Mustafa Tastekin ${ }^{3}$

\section{ABSTRACT}

Objective: The aim of this study was to examine the effect of temperature on fluoride uptake by enamel specimens from a $0.05 \%$ NaF-fluoridated mouthrinse (Oral-B Advantage; Oral-B Laboratories, Newbridge, UK).

Methods: Enamel specimens were prepared from extracted human maxillary central incisors. A fluoride-specific ion electrode was used to measure the uptake from a $2 \mathrm{ppm}$ fluoride solution containing $50.0 \mathrm{~mL}$ of distilled water, total ion strength adjustment buffer, and fluoridated rinse at 3 different temperatures (room temperature, $25^{\circ} \mathrm{C}$; human body temperature, $37^{\circ} \mathrm{C}$; hyper-fever temperature, $43^{\circ} \mathrm{C}$ ). One-way analysis of variance and least significant difference were used to assess intragroup and intergroup differences $(P<.05)$.

Results: The study found that both the amount and the rate of fluoride uptake increased significantly with increase in temperature. This effect was particularly noticeable at $43^{\circ} \mathrm{C}$.

Conclusions: The temperature of the NaF mouthrinse may easily and safely be increased beyond room temperature by placing a container of the NaF mouthrinse in a bowl of hot water, allowing greater fluoride penetration into the enamel from the mouthrinse when used at home as a routine prophylactic agent. (Eur J Dent 2012;6:361-369)

Key words: Fluoride uptake; temperature; enamel; mouthrinse

- 1 Department of Restorative Dentistry, Faculty of Dentistry, Kirikkale University, Kirikkale, TURKIYE

2 Department of Restorative Dentistry, Faculty of Dentistry, Ankara University, Ankara, TURKIYE

${ }_{3}$ Department of Chemistry, Faculty of Science, Ankara University, Ankara, TURKIYE

- Corresponding author: Dr. Serdar Baglar Department of Restorative Dentistry, Faculty of Dentistry, Kırıkkale University, Kurtulus Mh. Merkez, 71400 Kırıkkale, TURKIYE

Tel: +903182244927

Fax: +903182250685

Email: serdarbaglar78वgmail.com

\section{INTRODUCTION}

Fluoride penetration in the enamel occurs through the replacement of the relatively weak hydroxyl ions in the enamel mineral structure by the much more active fluoride ions, thereby improving the chemical stability of the enamel structure and making it more resistant to acids. ${ }^{1-4}$ The presence of fluoride in the oral cavity, especially in the saliva, has also been shown to have beneficial effects. ${ }^{5-8}$ For these reasons, a number of fluoride products with different contents and uptake levels 
have been developed to provide supplemental fluoride in various forms. After dentifrices, fluoride mouthrinses represent one of the most useful fluoride products. ${ }^{1,2,8-12}$ The fluoride mouthrinses commonly used today are neutral $\mathrm{pH}, 0.05 \% \mathrm{NaF}$, stable chemical compounds ${ }^{13}$ that act topically to decrease enamel decalcification and increase remineralization. ${ }^{14,15}$

The most important function of fluoridated agents is to increase the enamel resistance to acid by decreasing solubility through the incorporation of fluoride into the enamel apatite structure. Fluorapatite formation is based on a chemical equilibrium that allows the penetration of fluoride into the enamel. As with all chemical reactions, this process is strongly influenced by concentration and temperature. ${ }^{16}$ In a study examining the effects of heat on tin and fluoride uptake from topical $\mathrm{SnF}_{2}$ solutions by enamel samples prepared from extracted bovine teeth, Putt et $\mathrm{al}^{17}$ noted an increase in both tin and fluoride uptake with increase in temperature. Barrancos ${ }^{18}$ also found that higher temperatures enhanced fluoride uptake by the enamel from topical acidulated phosphate fluoride (APF) solutions. In study conducted using powdered enamel over a wide temperature range, Stearn and Berndt ${ }^{19}$ found APF solutions to be correlated with an increase in fluoride content and $\mathrm{CaF}_{2}$ formation. Stookey and Stahlman20 sug- gested that thermal changes resulting from friction were responsible for the enhanced fluoride uptake provided by fluoride-impregnated prophylactic cups.

In order to better understand the effects of temperature on fluoride uptake, this study compared the rates and amounts of fluoride uptake by the enamel from a fluoridated mouthrinse at 3 different temperatures.

\section{MATERIALS AND METHODS}

The chemical substances and equipment used in this study are listed in Tables 1 and 2, respectively.

\section{Preparation of the Specimens}

A total of 30 extracted human maxillary central incisors were used in the study. All the teeth were visually examined to ensure that they were free from apparent caries, macroscopic cracks, abrasion, and excessive staining on the lingual and buccal surfaces. Prior to use, the teeth were cleaned by gentle brushing with a fluoride-free toothpaste and stored in distilled water containing $0.1 \%$ thy$\mathrm{mol}$ at $4^{\circ} \mathrm{C}$. The crowns were separated from the roots $2 \mathrm{~mm}$ above the cemento-enamel junction and sectioned mesiodistally; then, the labial surfaces were sectioned into 3 slabs by using a diamond saw (Isomet; Buehler, Lake Bluff, IL, USA). The inner surfaces of each section were abraded

Table 1. Chemical materials used in the experiment.

\begin{tabular}{lr}
\hline MATERIAL & MANUFACTURER \\
\hline TISAB & Ank. Univ. Department of Chemistry, Faculty of Science, Analytical Chemistry Laboratory \\
\hline Ultra Distilled Water & Ank. Univ. Department of Chemistry, Faculty of Science, Analytical Chemistry Laboratory \\
$\begin{array}{l}\text { Mouthrinse }(0.05 \% \mathrm{NaF}) \\
\text { Acetic Acid }(99.5 \%)\end{array}$ & Oral-B Advantage, Oral-B Laboratories, Newbridge, UK. \\
$\mathrm{NaCl}(99.5 \%)$ & Merck (100056) Darmstadt, Germany \\
$\mathrm{NaOH}($ High purity) & Merck (106404) Darmstadt, Germany \\
Standard fluoride solution $(100 \mathrm{ppm})$ & Merck (106462) Darmstadt, Germany \\
\hline
\end{tabular}

Table 2. Equipment used in the experiment.

\begin{tabular}{|c|c|}
\hline EQUIPMENT & MANUFACTURER \\
\hline Combined fluoride ion selective electrode & Orion Model 96-09, Orion Research, Boston, MA, U.S.A \\
\hline Glass electrode & Orion Model 91 Series, $\mathrm{Ag} / \mathrm{AgCl} \mathrm{pH}$ electrode, Boston, M.A, U.S.A \\
\hline Automatic pipette $100 \mu \mathrm{L}-1000 \mu \mathrm{L}$ & Brand, $\pm 5 \mu \mathrm{L}$, measured with accuracy, Germany \\
\hline Automatic pipette $0.5 \mu \mathrm{L}-5 \mu \mathrm{L}$ & Brand, $\pm 0.02 \mu \mathrm{L}$, measured with accuracy, Germany \\
\hline Potentiometer & Consort C863 Multi - parameter analyser, Parklaan, Belgium \\
\hline Magnetic Stirrer & Chiltron hotplate, magnetic stirrer HS31 Scientific Wendurer, England \\
\hline Circulating water bath pump & Nüve BM 102 Industrial Supplies and Trading Company Ankara, Turkey \\
\hline Analytical Balance & Gec Avery, Model, VA304, 0,1 mg measured with accuracy, UK \\
\hline
\end{tabular}


using wet 360- and 600-grit silicon carbide paper to remove any remaining dentin, and the slabs were examined under a stereomicroscope (Leica MZ12; Leica AG, CH-9435 Heerbrugg, Switzerland) to confirm that they consisted of enamel alone. All specimens were stored in distilled water until the experiment.

Specimens were randomly divided into 3 groups ( $n=30$ ) for treatment at different temperatures, namely, room temperature, $25^{\circ} \mathrm{C}$; human body temperature, $37^{\circ} \mathrm{C}$; and hyper-fever temperature, $43^{\circ} \mathrm{C}$. Each group was further divided into 3 subgroups ( $n=10$ ) to demonstrate the reproducibility of the measurements in each temperature group, and the average mass of each subgroup was calibrated $(0.7412 \pm 0.0043 \mathrm{~g})$ using an analytical balance to ensure standardization (Table 3). The slabs were stored in distilled water in polyethylene tubes that had been previously washed with distilled water, rinsed with bidistilled water, and dried in a sterilizer oven on blotting paper.

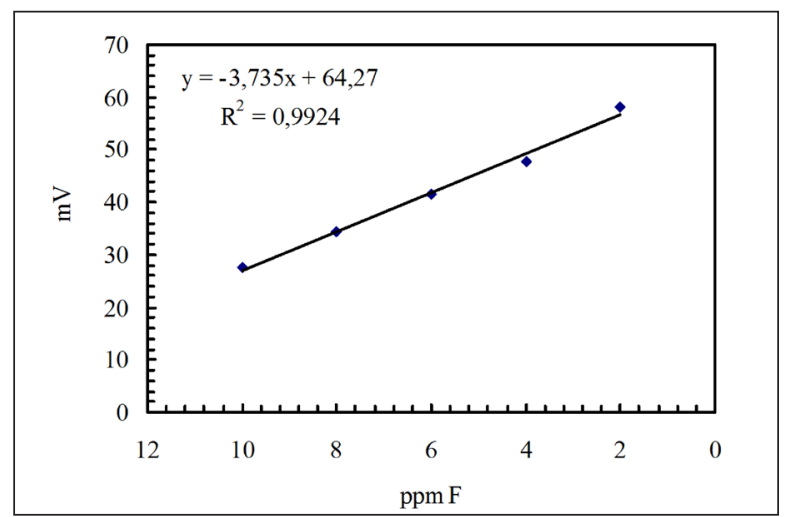

Figure 1. Calibration graph used to determine fluoride content of mouthrinse.

Table 3. Subgroups of enamel specimens and their masses.

\begin{tabular}{|c|c|c|}
\hline $25^{\circ} \mathrm{C}$ Enamel & $37^{\circ} \mathrm{C}$ Enamel & $43^{\circ} \mathrm{C}$ Enamel \\
\hline Specimens & Specimens & Specimens \\
\hline I. Subgroup & I. Subgroup & I. Subgroup \\
\hline $1 a, 2 a, 3 a, 4 a, 5 a$ & $1 b, 2 b, 3 b, 4 b, 5 b$ & $1 c, 2 c, 3 c, 4 c, 5 c$ \\
\hline $6 a, 7 a, 8 a, 9 a, 10 a$ & $6 b, 7 b, 8 b, 9 b, 10 b$ & $6 c, 7 c, 8 c, 9 c, 10 c$ \\
\hline$\Sigma=0.7355 \mathrm{~g}$ & $\Sigma=0.7424 \mathrm{~g}$ & $\Sigma=0.7386 \mathrm{~g}$ \\
\hline II. Subgroup & II. Subgroup & II. Subgroup \\
\hline 11a, 12a, 13a, 14a, 15a, & $11 b, 12 b, 13 b, 14 b, 15 b$ & $11 c, 12 c, 13 c, 14 c, 15 c$ \\
\hline $16 a, 17 a, 18 a, 19 a, 20 a$ & $16 b, 17 b, 18 b, 19 b, 20 b$ & $16 c, 17 c, 18 c, 19 c, 20 c$ \\
\hline$\Sigma=0.7461 \mathrm{~g}$ & $\Sigma=0.7456 \mathrm{~g}$ & $\Sigma=0.7461 \mathrm{~g}$ \\
\hline III. Subgroup & III. Subgroup & III. Subgroup \\
\hline $21 a, 22 a, 23 a, 24 a, 25 a$, & $21 b, 22 b, 23 b, 24 b, 25 b$ & $21 c, 22 c, 23 c, 24 c, 25 c$ \\
\hline $26 a, 27 a, 28 a, 29 a, 30 a$ & $26 b, 27 b, 28 b, 29 b, 30 b$ & $26 c, 27 c, 28 c, 29 c, 30 c$ \\
\hline$\Sigma=0.7386 \mathrm{~g}$ & $\Sigma=0.7371 \mathrm{~g}$ & $\Sigma=0.7411 \mathrm{~g}$ \\
\hline
\end{tabular}

\section{Fluoride Measurement}

A fluoride-specific ion electrode (Orion model 96-09; Orion Research, Boston, MA, USAl was used to measure the fluoride concentrations. The total ion strength adjustment buffer (TISAB) was used as a stabilizer. ${ }^{7,20}$

Preparation of Calibration Solution from Standard Fluoride Solution

A standard 100 ppm fluoride solution (Orion Research 940907, Boston, MA., USA) was used to prepare the calibration solutions. ${ }^{7,21}$ In order to establish calibration graphs, $50 \mathrm{~mL}$ of the calibration solutions were prepared using $25 \mathrm{~mL}$ of TISAB solution and $25 \mathrm{~mL}$ of $2,4,6$, and 8 ppm fluoride solutions prepared from a standard fluoride solution of 100 ppm fluoride and distilled water. The actual fluoride content of the mouthrinse was determined using the calibration graph constructed from the calibration solutions (Figure 1).

Calibration of the Mouthrinse Fluoride Solution Using the standard solution calibration graph $\left(R^{2}=0.9924\right)$, the fluoride concentration of the mouthrinse was determined to be 235 ppm, which is similar to the measurement reported by the manufacturer (230 ppm). On the basis of this calibration graph, the rinse volumes were calculated for solutions of $0.5,1.0,1.5,2.0$, and 2.5 ppm fluoride. Calibration graphs for all the temperatures were constructed for determining the fluoride uptake by the enamel from the mouthrinse solution.

Table 4 shows the fluoride ppm and the corresponding mouthrinse volumes for $50 \mathrm{~mL}$ of the calibration solutions.

\section{October 2012 - Vol.6}


Separate solutions were prepared for each temperature at all ppm values. The $\mathrm{mV}$ values were recorded from the potentiometer screen after the readings stabilized. Calibration graphs for $25^{\circ} \mathrm{C}, 37^{\circ} \mathrm{C}$, and $43^{\circ} \mathrm{C}$ are shown in Figures 2,3 , and 4 , respectively.

Determination of Fluoride Uptake by the Enamel from the Mouthrinse Solution

Circulation water bath temperatures were adjusted for all temperatures and subgroups. Test solutions of $0.426 \mathrm{~mL}$ of the fluoride mouthrinse were freshly prepared for each subgroup. Different pipettes were used for TISAB, distilled water, and the mouthrinse. Magnetic stirrers and small magnets were used to maintain the stability and integrity of the solutions. New magnets and containers were used for each experiment. All ex-

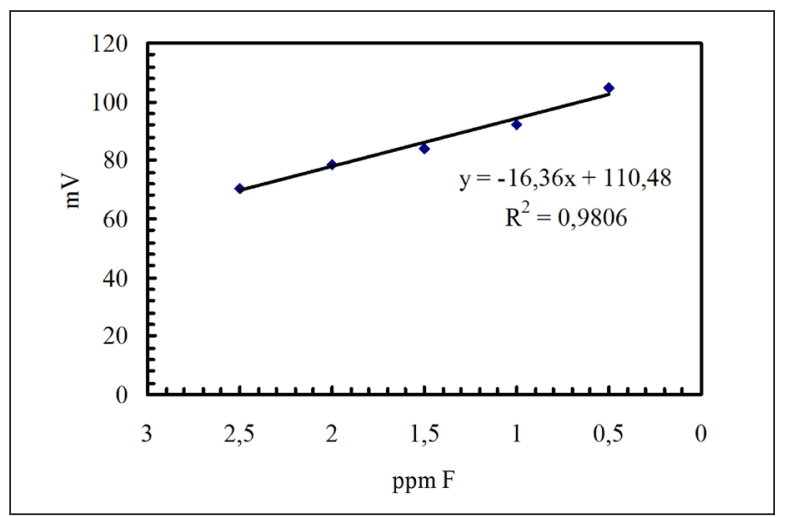

Figure 2. Calibration graph $\left(25^{\circ} \mathrm{C}\right)$.

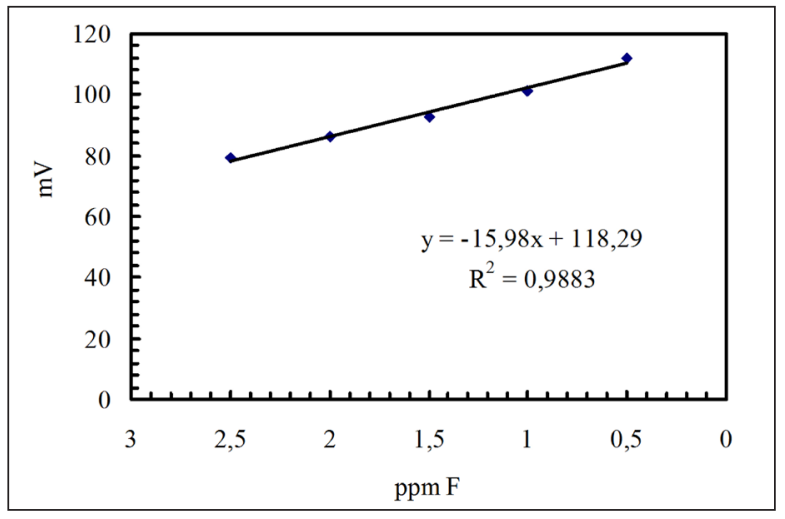

Figure 3. Calibration graph $\left(37^{\circ} \mathrm{C}\right)$.

Table 4. 50m calibration solutions (fluoride ppm and mouthrinse volume). periments were performed using freshly prepared solutions. ${ }^{22}$ Temperature sensors, thermometers, and fluoride-specific electrodes were held in place in the solutions by using fixed holders. The surfaces of the electrodes and the temperature equipment were washed with distilled water and dried between groups. The fluoride content of each solution was measured using a potentiometer and recorded prior to the addition of the enamel specimens at 15 -s intervals up to $1 \mathrm{~min}, 1-\mathrm{min}$ intervals from 1 to $10 \mathrm{~min}, 5$-min intervals from 10 to $50 \mathrm{~min}$, and 10 -min intervals from 50 to 120 $\mathrm{min}$. The fluoride uptake by the enamel specimens was calculated in $\mathrm{mV}$ by subtracting the measured concentration from the previously measured concentration before the addition of the specimens. The same procedures were repeated for all the temperatures and subgroups.

Fluoride-ion activity potential was measured in $\mathrm{mV}$ by using a potentiometer. The calibration graphs were constructed with $\mathrm{mV}$ values on the $y$ axis and the ppm $\mathrm{F}^{-}$values on the $\mathrm{x}$-axis; the ppm $\mathrm{F}^{-}$values were calculated using the equation $\mathrm{y}=$ $m x+n$.

\section{Statistical Analysis}

The uptake of fluoride by the enamel specimens from the mouthrinse was measured and recorded from 15 s to $120 \mathrm{~min}$. Graphs of the fluoride uptake for each temperature group were drawn,

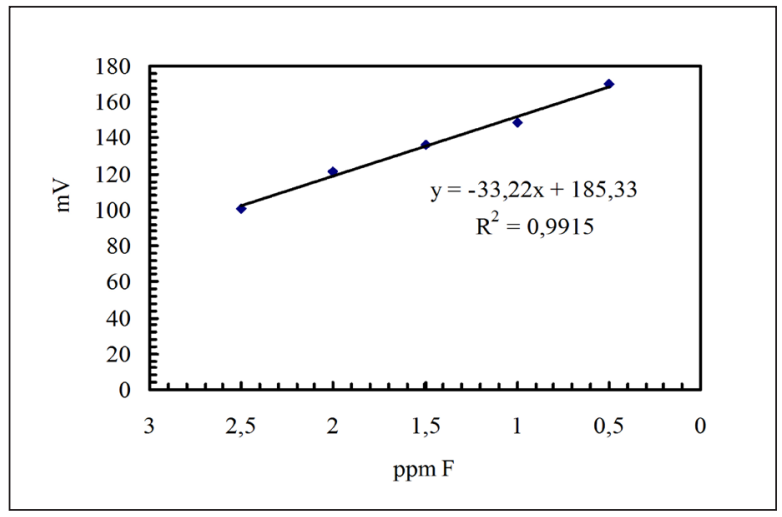

Figure 4. Calibration graph $\left(43^{\circ} \mathrm{C}\right)$

\begin{tabular}{lc}
\hline F ppm & $\mathrm{mL}$ mouthrinse \\
\hline 0,5 & 0.106 \\
1 & 0.213 \\
1,5 & 0.319 \\
2 & 0.426 \\
2,5 & 0.532 \\
\hline
\end{tabular}


and intragroup and intergroup comparisons were assessed using one-way analysis of variance and the least significant difference, with the level of significance set at $P<.05$.

\section{RESULTS}

The fluoride absorption by the enamel specimens from the mouthrinse was found to increase with increase in temperature (Table 5).

\section{Enamel Fluoride Concentrations at $25^{\circ} \mathrm{C}$}

The changes in the $\mathrm{mV}$ and $\mathrm{ppm}$ values of the fluoride solution at $25^{\circ} \mathrm{C}$ are shown in Figures 5

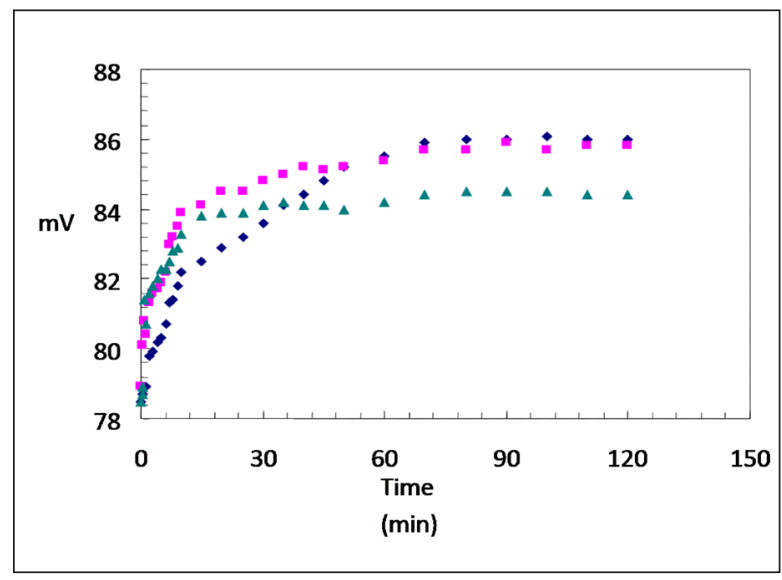

Figure 5. Changes $(\mathrm{mV})$ in fluoride solution $25^{\circ} \mathrm{C} \quad$ :Isubgroup; :Ill.subgroup)

Table 5. Enamel fluoride uptake from mouth rinse, by temperature/time.

\begin{tabular}{|c|c|c|c|c|c|c|c|c|c|c|c|c|c|c|}
\hline Temperature & & & & & & & Time & /ppm & & & & & & \\
\hline${ }^{\circ} \mathrm{C}$ & $15 s$ & $30 \mathrm{~s}$ & $45 s$ & $1 \mathrm{~m}$ & $2 m$ & $3 m$ & $4 m$ & $5 m$ & $6 \mathrm{~m}$ & $7 m$ & $8 m$ & $9 m$ & $10 \mathrm{~m}$ & $15 m$ \\
\hline \multirow{3}{*}{25} & 2 & 2 & 2 & 2 & 1,967 & 1,9364 & 1,967 & 1,9303 & 1,9181 & 1,9181 & 1,8936 & 1,8753 & 1,8444 & 1,8395 \\
\hline & 1,857 & 1,857 & 1,8386 & 1,8142 & 1,7836 & 1,7836 & 1,7592 & 1,7531 & 1,7286 & 1,6797 & 1,6797 & 1,6553 & 1,6347 & 1,6264 \\
\hline & 1,9364 & 1,9303 & 1,8203 & 1,7775 & 1,7653 & 1,7531 & 1,7408 & 1,7225 & 1,7225 & 1,7103 & 1,6919 & 1,6858 & 1,6614 & 1,6309 \\
\hline \multirow{3}{*}{37} & 1,9561 & 1,9249 & 1,8998 & 1,7934 & 1,7058 & 1,6245 & 1,6244 & 1,5932 & 1,5619 & 1,5431 & 1,5118 & 1,4931 & 1,4757 & 1,4538 \\
\hline & 1,9624 & 1,9437 & 1,8748 & 1,831 & 1,7309 & 1,649 & 1,6245 & 1,5931 & 1,5557 & 1,5182 & 1,4806 & 1,4493 & 1,4276 & 1,4074 \\
\hline & 1,9437 & 1,8999 & 1,8686 & 1,7935 & 1,7372 & 1,6308 & 1,587 & 1,5433 & 1,5119 & 1,4744 & 1,4306 & 1,3868 & 1,3354 & 1,2854 \\
\hline \multirow{3}{*}{43} & 1,6626 & 1,5181 & 1,3645 & 1,2532 & 1,1358 & 1,0545 & 0,9552 & 0,9341 & 0,8769 & 0,8438 & 0,8378 & 0,8197 & 0,8107 & 0,7987 \\
\hline & 1,5993 & 1,4729 & 1,2863 & 1,1448 & 1,0394 & 0,9551 & 0,8739 & 0,8047 & 0,7444 & 0,6993 & 0,6722 & 0,6512 & 0,6421 & 0,6301 \\
\hline & 1,6896 & 1,5542 & 1,4548 & 1,3314 & 1,208 & 1,1026 & 0,9913 & 0,8739 & 0,7715 & 0,6873 & 0,6331 & 0,6241 & 0,615 & 0,603 \\
\hline \multirow[t]{2}{*}{$\mathrm{oC}$} & $20 m$ & $25 m$ & $30 \mathrm{~m}$ & $35 m$ & $40 \mathrm{~m}$ & $45 m$ & $50 \mathrm{~m}$ & $60 \mathrm{~m}$ & $70 \mathrm{~m}$ & $80 m$ & $90 \mathrm{~m}$ & $100 \mathrm{~m}$ & $110 \mathrm{~m}$ & $120 \mathrm{~m}$ \\
\hline & 1,8017 & 1,8123 & 1,7918 & 1,7652 & 1,7487 & 1,7118 & 1,7101 & 1,6856 & 1,6608 & 1,6575 & 1,6575 & 1,6571 & 1,657 & 1,657 \\
\hline \multirow[t]{3}{*}{25} & 1,6264 & 1,5962 & 1,5736 & 1,5642 & 1,5546 & 1,5527 & 1,5427 & 1,5218 & 1,5074 & 1,5074 & 1,5007 & 1,5074 & 1,5035 & 1,5035 \\
\hline & 1,6247 & 1,6247 & 1,6125 & 1,6064 & 1,6124 & 1,6125 & 1.610 & 1,6063 & 1,5941 & 1,588 & 1,588 & 1,588 & 1,594 & 1,594 \\
\hline & 1,4326 & 1,4219 & 1,3854 & 1,3548 & 1,3365 & 1,2847 & 1,2687 & 1,2133 & 1,1675 & 1,1345 & 1,078 & 1,0321 & 0,9989 & 0,9982 \\
\hline \multirow[t]{3}{*}{37} & 1,3762 & 1,3012 & 1,2738 & 1,2437 & 1,1987 & 1,1439 & 1.249 & 1,0623 & 0,9964 & 0,9265 & 0,8867 & 0,8127 & 0,7964 & 0,7887 \\
\hline & 1,1997 & 1,1128 & 1,0768 & 1,0325 & 0,9978 & 0,9765 & 0,9565 & 0,9417 & 0,9265 & 0,8953 & 0,8417 & 0,8123 & 0,8053 & 0,8067 \\
\hline & 0,7806 & 0,7716 & 0,7595 & 0,7505 & 0,7415 & 0,7415 & 0.740 & 0,7384 & 0,7233 & 0,7083 & 0,7143 & 0,7143 & 0,7173 & 0,7203 \\
\hline \multirow[t]{2}{*}{43} & 0,615 & 0,606 & 0,5999 & 0,594 & 0,591 & 0,591 & 0,594 & 0,597 & 0,597 & 0,5999 & 0,597 & 0,597 & 0,5999 & 0,5999 \\
\hline & 0,5879 & 0,5699 & 0,5639 & 0,5548 & 0,5488 & 0,5428 & 0,5388 & 0,5338 & 0,5338 & 0,5428 & 0,5368 & 0,5397 & 0,5398 & 0,5398 \\
\hline
\end{tabular}

and 6 , respectively. At $25^{\circ} \mathrm{C}$, most of the reduction in the solution's fluoride concentration occurred in the first $16 \mathrm{~min}$, during which the concentration decreased at a rate of approximately $20 \%$ to 1.60 ppm. At $50 \mathrm{~min}$, the mean fluoride concentration had decreased to $1.56 \mathrm{ppm}(23 \%)$ and at $120 \mathrm{~min}$, the mean fluoride concentration had decreased to $1.52 \mathrm{ppm}$ (25\%). Differences in the rate of change in fluoride concentrations were significant up 70 $\min (P<.05)$ but they were not significant from 70 $\min$ to $120 \mathrm{~min}(P>$.05).

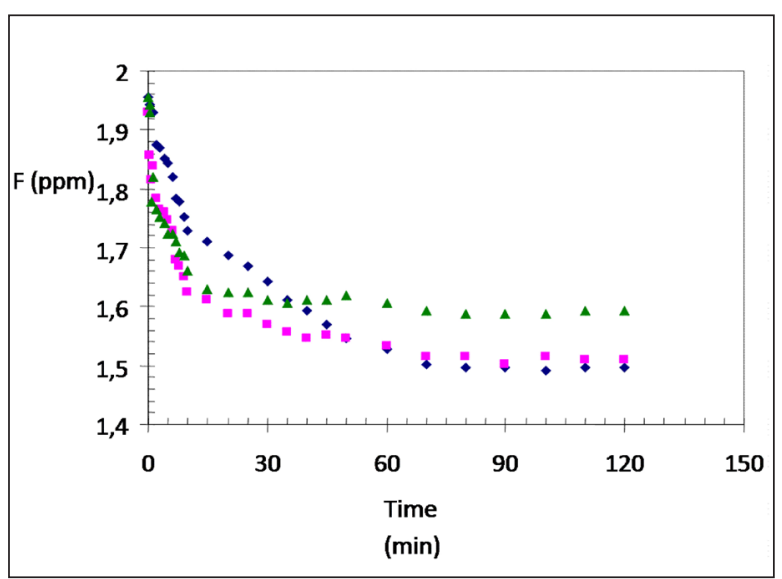

Figure 6. Changes in fluoride uptake (ppm) by enamel from solution at $25^{\circ} \mathrm{C}($ : 1 . subgroup ; I: II. subgroup; $\mathbf{A}$ : III. Subgroup). 


\section{Enamel Fluoride Concentrations at $37^{\circ} \mathrm{C}$}

Changes in the $\mathrm{mV}$ and ppm values of the fluoride solution at $37^{\circ} \mathrm{C}$ are shown in Figures 7 and 8 , respectively. At $37^{\circ} \mathrm{C}$, most of the reduction in the solution's fluoride concentration occurred in the first $12 \mathrm{~min}$, during which the fluoride concentration of the solution decreased at a rate of approximately $30 \%$ to $1.4 \mathrm{ppm}$. At $50 \mathrm{~min}$, the mean fluoride concentration had decreased to $1.00 \mathrm{ppm}$ $(50 \%)$ and at $120 \mathrm{~min}$, the mean fluoride concentration had decreased to 0.7 ppm (65\%). Differences in the rate of change in fluoride concentrations were significant up to $60 \mathrm{~min}(\mathrm{P}<.05)$ but they were not significant from $60 \mathrm{~min}$ to $120 \mathrm{~min}(\mathrm{P}>.05)$.

\section{Enamel Fluoride Concentrations at $43^{\circ} \mathrm{C}$}

Changes in the $\mathrm{mV}$ and ppm values of the fluoride solution at $43^{\circ} \mathrm{C}$ are shown in Figures 9 and 10 , respectively. At $43^{\circ} \mathrm{C}$, most of the reduction in the solution's fluoride concentration occurred in the first $5 \mathrm{~min}$, during which the fluoride concentration of the solution decreased at a rate of ap-

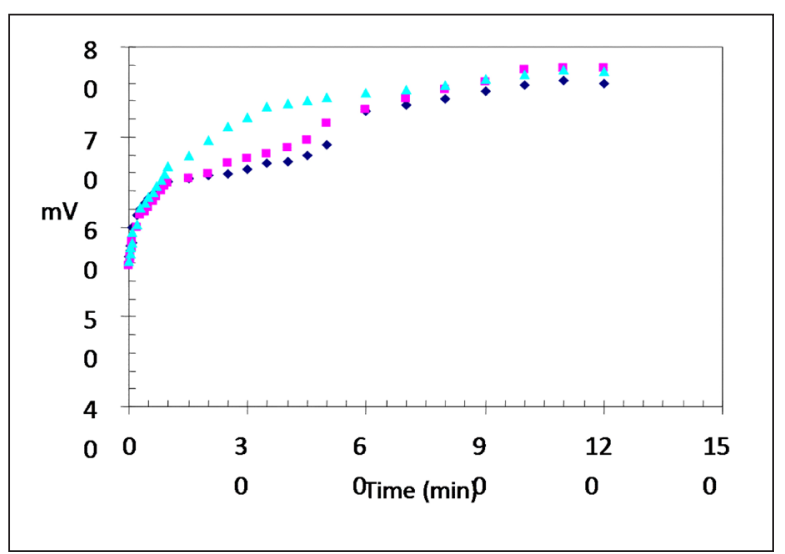

Figure 7. Changes $(\mathrm{mV})$ in fluoride solution $37^{\circ} \mathrm{C}$ :I.subgroup; $\mathbf{1}$ :I.subgroup; $\mathbf{\Delta}$ :IIl.subgroup).

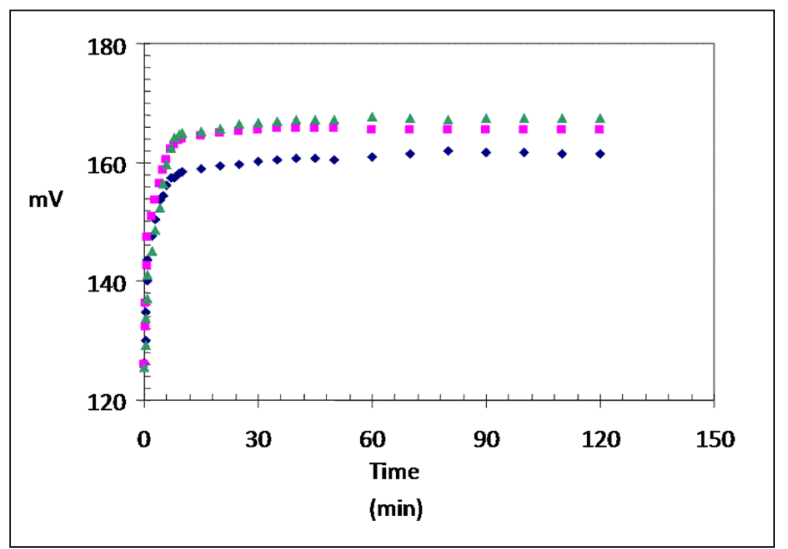

Figure 9. Changes $(\mathrm{mV})$ in fluoride solution at $43^{\circ} \mathrm{C}$ (I.subgroup; :IIl.subgroup). proximately $65 \%$ to $0.7 \mathrm{ppm}$. At $50 \mathrm{~min}$, the mean fluoride concentration had decreased to $0.60 \mathrm{ppm}$ $(70 \%)$, and no further changes in concentration were observed. Differences in the rate of change in fluoride concentrations were significant up 50 min $(P<.05)$ but they were not significant from 50 $\min$ to $120 \mathrm{~min}(P>$.05).

A Comparison of the Fluoride Uptake by the Enamel Specimens at Different Temperatures

Regardless of temperature, fluoride uptake occurred most rapidly during the first few minutes, after which it decreased until the enamel reached saturation. Moreover, the speed and amount of fluoride uptake increased with temperature, with majority of the fluoride uptake at $25^{\circ} \mathrm{C}$ occurring during the first $16 \mathrm{~min}$, compared to the first 12 $\min$ at $37^{\circ} \mathrm{C}$ and the first $5 \mathrm{~min}$ at $43^{\circ} \mathrm{C}$. Significant increase occurred in the rate of uptake until $70 \mathrm{~min}$ at $25^{\circ} \mathrm{C}, 60 \mathrm{~min}$ at $37^{\circ} \mathrm{C}$, and $50 \mathrm{~min}$ at $43^{\circ} \mathrm{C}$ $(\mathrm{P}<.05)$, after which the changes were not statistically significant.

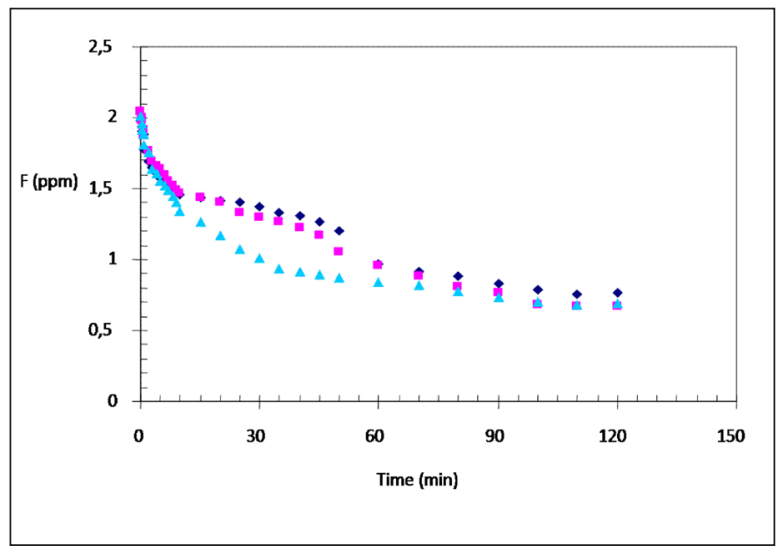

Figure 8. Changes in fluoride uptake (ppm) by enamel from solution at $37^{\circ} \mathrm{C}($ : $)$ subgroup ; : II. subgroup; $\mathbf{A}$ : III. Subgroup).

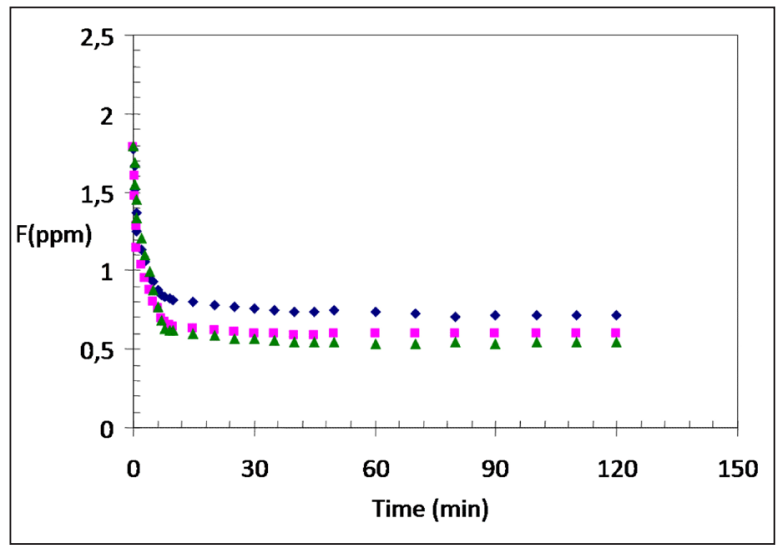

Figure 10. Changes in fluoride uptake (ppm) by enamel from solution at $43^{\circ} \mathrm{C}($ : I. subgroup ; 드: II. subgroup; $\mathbf{A}$ : III. Subgroup). 


\section{DISCUSSION}

The present study examined the effect of temperature on fluoride uptake by enamel specimens from a mouthrinse. In order to ensure comparability between groups, utmost care was taken in the preparation of the samples to provide standardization of volume and mass. Numerous studies have relied on fluoride-specific ion electrodes for measuring the fluoride uptake. 1,7,23-28 Our study also utilized a fluoride-specific ion electrode as a practical, economical, and accurate measuring tool.

Fluoride mouthrinses may be categorized by $\mathrm{NaF}$ concentrations as either low concentration (230 ppm, 0.05\%) or high concentration $(900$ ppm, $0.2 \%) .{ }^{29}$ In addition to NaF formulations, SnF2, amine fluoride, and ammonium fluoride mouth-

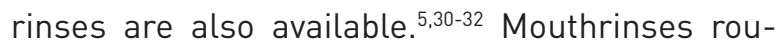
tinely available on the market tend to be low-concentration, neutral-pH, 0.05\% NaF solutions. ${ }^{12,33,34}$ In this study, a $0.05 \% \mathrm{NaF}$ mouthrinse solution was chosen because it possessed a stable structure, almost neutral $\mathrm{pH}$, and high solubility; did not cause enamel discoloration (as with $\mathrm{SnF}_{2}$ ); and was readily available on the market.

In line with many earlier studies, our study found that majority of the fluoride uptake by the enamel specimens occurred during the first minutes following application and continued over time. Moreover, our study showed that increasing the temperature of the fluoride solution resulted in an increase in the fluoride uptake by the enamel specimens as well as a decrease in the time needed to reach saturation. Fluoride absorption was found to cease at around $60 \mathrm{~min}$; however, measurements continued until $120 \mathrm{~min}$ to control for additional changes/recycling.

Mouthrinse has been reported to be one of the most effective methods of providing low but consistent fluoride levels in the oral cavity. 6,32,35,36 As with other fluoride preparations, fluoridated mouthwashes are designed to increase the level of fluoride released in the saliva and maintain it at a certain level. ${ }^{37}$ Most importantly, fluoridated agents are able to increase the resistance and decrease the solubility of the enamel to acids through the incorporation of fluoride ions into the enamel apatite structure.

As with all chemical reactions, the degree and speed of penetration of fluoride into the enamel and the formation of fluorapatite are strongly de- pendent upon concentration and temperature. ${ }^{16}$ However, very few studies have examined the effect of temperature on fluoride uptake by the enamel from a mouthrinse. Barrancos ${ }^{18}$ reported that fluoride absorption increases with increase in room temperature, and Stookey and Stahlman $^{20}$ showed that uptake from a fluoride solution could be increased by raising the temperature of the storage container by scrubbing. Moreover, in a study examining the effects of heat $\left(25^{\circ} \mathrm{C}, 45^{\circ} \mathrm{C}\right.$, $65^{\circ} \mathrm{C}$, and $85^{\circ} \mathrm{C}$ ) on tin and fluoride uptake from a topical $\mathrm{SnF}_{2}(8 \%)$ solution by enamel samples prepared from extracted bovine teeth, Putt et al ${ }^{17}$ reported increase in both fluoride and tin uptake in line with increase in temperature, with the most significant increase in fluoride content observed at $65^{\circ} \mathrm{C}$ and $85^{\circ} \mathrm{C}$. Our study used a $0.05 \% \mathrm{NaF}$ solution and examined temperatures up to only $43^{\circ} \mathrm{C}$, the body's hyper-fever limit. Nevertheless, in line with these previous studies, significant increase in fluoride uptake was observed with increase in temperature.

\section{CONCLUSIONS}

Our study found that the amount and rate of fluoride uptake by tooth enamel increased with increase in temperature. The temperature of $\mathrm{NaF}$ mouthrinse may easily and safely be increased beyond room temperature by placing a container of NaF mouthrinse in a bowl of hot water, allowing greater fluoride penetration into the enamel when the mouthrinse is used at home as a routine prophylactic agent. It should be noted that fluoride absorption and release may change depending upon an individual's dental structure and eating habits. Other studies are required to examine the effects of temperature on fluoride uptake in the enamels of different populations from other mouthrinse derivatives and at different temperatures and application times.

\section{REFERENCES}

1. Buchalla W, Attin T, Schülte-Mönting J, Hellwig E. Fluoride uptake, retention, and remineralization efficacy of a highly concentrated fluoride solution on enamel lesions in situ. $J$ Dent Res 2002;81:329-333.

2. Silva MF, Giniger MS, Zhang YP, Devizio W. The effect of a triclosan\copolymerlfluoride liquid dentifirice on interproximal enamel remineralization and fluoride uptake. $J$ Am Dent Assoc 2004;135:1023-1029. 
3. Bijella MJ, Brighenti FL, Bijella MF, Buzalof MA. Fluoride kinetics in saliva after the use of a fluoride-containing chewing gum. Braz Oral Res 2005;19:1-9.

4. Bayrak S, Tunc ES, Aksoy A, Ertas E, Guvenc D, Ozer S. Fluoride release and recharge from different materials used as fissure sealants. Eur J Dent. 2010;4:245-250.

5. Hong YC, Chow LC, Brown WE. Basic Biological Sciences: Enhanced fluoride uptake from mouthrinses. $J$ Dent Res 1985;64:82-84.

6. Gordan VV, Mjör JA. Short and long-term clinical evaluation of post-operative sensitivity of a new resin-based restorative material and self-etching primer. Oper Dent 2002;27:543-548.

7. Altenburger MJ, Schirrmeister JF, Lussi, A, Klasser M, Hellwig E. In-situ fluoride retention and remineralization of incipient carious lesions after the application of different concentrations of fluoride. Euro J Oral Sci 2009;117:58-63.

8. Sener Y, Tosun G, Kahvecioglu F, Gökalp A, Koç H. Fluoride levels of human plasma and breast milk. Eur J Dent. 2007:1:21-24

9. Brambilla E. Fluoride-is it capable of fighting old and new dental diseases? An overview of existing fluoride compounds and their clinical applications. Caries Res 2001;35:69.

10. Leverett DH. Effectiveness of mouthrinsing with fluoride solutions in preventing coronal and root caries $J$ Pub Health Dent 1989;49:310-316.

11. Twetman S, Petersson L, Axelsson S, Dahlgren H, Holm AK, Kallestal C. Caries-preventive effect of sodium fluoride mouthrinses: a systematic review of controlled clinical trials. Acta Odontol Scand 2004;62:223-230.

12. Celik C, Yuzugullu B, Erkut S, Yamanel K. Effects of Mouth Rinses on Color Stability of Resin Composites. Eur J Dent 2008 Oct;2:247-253.

13. Ripa LW. Rinses for the control of dental caries. Int Dent $J$ 1992;42:263-269

14. Denes J, Gabris K. Results of a 3-year oral hygiene programme, including amine fluoride products, in patients treated with fixed orthodontic appliances. Eur J Orthod 1991;13:129-133

15. Boyd RL. Two-year longitudinal study of a peroxide-fluoride rinse on decalcification in adolescent orthodontic patients. J Clin Dent 1992;3:83-87.

16. Skoog DA, West DM, Holler FJ. Fundamentals of Analytical Chemistry.8th ed. Saunders Collage Publishing, USA; 1997:621-26.

17. Putt MS, John FB, Joseph CM. Effect of Temperature of SnF2 Solution on Tin and Fluoride Uptake by Bovine Enamel J Dent Res 1978;57:772-776.
18. Barrancos RJ. Effects of temperature on the uptake of topical fluorides, Master of Sciences Thesis, The University of Michigan.1966

19. Stearns RL, Berndt AF. Reaction of acidulated phosphate-fluoride solutions with human apatite. J Dent Res 1973;52:1253-1260.

20. Stookey GK, Stahlman DB. Enhanced fluoride uptake in enamel with a fluoride-containing prophylactic cup. J Dent Res 1976;55:333-341.

21. De Witte AM, De Maeyer EA, Verbeeck RM, Martens LC. Fluoride release profiles of mature restorative glass ionomer cements after fluoride application. Biomaterials 2000;21:475-482.

22. Gao W, Smales RJ. Fluoride release/uptake of conventional and resin-modified glass ionomers and compomers. J Dent 2001;29:301-306.

23. McCabe JF. Resin-modified glass ionomers. Biomaterials 1998;19:521-527.

24. Billington RW, Hadley PC, Williams JA, Pearson GJ. Kinetics of fluoride release from zinc oxide-based cements. Biomaterials 2001;22:2507-2513.

25. Durst RA. Fluoride microanalysis by linear null-point. Anal Chem 1968;40931-935.

26. Raby AB, Sunderland WB. Direct determination of fluoride in tungsten using the fluoride ion activity electrode. Anal Chem 1967;39:1304-1305.

27. Singer L, Armstrong WD. The potential fluoride analysis from bone subjects. Anal Chem 1968;40:613-617.

28. Phillips KA, Rix CJ. Microprocessor-controlled determination of fluoride in environmental and biological samples by a method of standart additions with a fluoride ion selective electrode. Anal Chem 1981;53:2141.

29. Malde MK, Zerihun L, Julshamn K, Bjorvatn K. Fkuoride, calcium and magnesium intake in children living in a highfluoride area in Ethiopia. Intake through food. Int $J$ Paed Dent 2004;14:167-174.

29. Clarkson JJ, McLoughlin J. Role of fluoride in oral health promotion Int Dent $J$ 2000;50:119-128.

30. Gordan VV, Mjör JA, Hucke RD, Swith GE. Effect of different liner treatment on post operative sensitivity of amalgam restorations. Quintessence Int 1999;30:55-59.

31. Sieck B, Takagi S, Chow LC. Assessment of loosely-bound and firmly-bound fluoride uptake by tooth enamel from topically applied fluoride treatments. J Dent Res 1990;69:12611265.

32. Geiger S, Matalon S, Blasbalg J, Tung MS, Eichmiller FC. The clinical effect of amorphous calcium phosphate on root surface hypersensitivity. Oper Dent 2003;28:496-500.

33. Winston AE, Bhaskar SN. Caries prevention in the 21 st century. JADA 1998;129:1579-1587. 
34. Featherstone JD. The science and practice of caries prevention. JADA 2000;131:887-899.

35. Tung MS, Bowen HJ, Derkson GD, Pashley DH. Effects of calcium phosphate solutions on dentine permeability. $J$ Endod 1993;19:383-387.

36. Morris MF, Davis RD, Richardson BW. Clinical efficacy of two dentine desensitizing agents. Am J Dent 1999;12:72-76.

37. Petersson LG. Fluoride mouthrinses and fluoride varnishes. Caries Res 1993;27:35-42. 